\title{
"Professora, vem ver! O Paulo vai ter neném!": gênero, sexualidade e formação de professores/as
}

"Teacher, come here! Paulo is gonna have a baby": gender, sexuality and teacher's training

Tiago Duque*

Universidade Federal de Mato Grosso do Sul

Resumo Este texto discute diferentes experiências que revelam compreensões, dilemas e facilidades diante da questão de gênero e sexualidade na formação de professores/as. Principalmente através de uma perspectiva teórica pós-estruturalista, aqui se pensam as experiências vividas pelo autor referentes a relatos (seus contextos e significados) que foram colhidos durante o seu trabalho como professor universitário, pesquisador no campo do gênero e da sexualidade e militante em prol da diversidade sexual. Com essas práticas educativas refletidas teoricamente, conclui-se que um início possível para discutir formação de professores/as e questões de gênero e sexualidade é, a partir dos estranhamentos às transgressões nas salas de aula, deixar emergir a diferença e pensá-la criticamente em busca de experiências ainda não vividas, e não necessariamente em busca de um respeito à diversidade.

Palavras-Chave: Gênero, Sexualidade, Formação de Professores.

Abstract This paper discusses various experiments that reveal understandings, dilemmas and eases on the issue of gender and sexuality in teacher's training. Mainly through a post-structuralist theoretical perspective, here it is discussed the author's experiences regarding reports (their contexts and meanings) that have been collected during his work as a university professor, researcher in the field of gender and sexuality and militant towards sexual diversity. With these educational practices reflected theoretically, it is concluded that a possible way to start thinking teacher education and issues of gender and sexuality is from strangeness to transgressions in classrooms, let emerge the difference and think about it critically in search of experiences not lived yet and not necessarily in search of a respect for diversity.

KEYWORDS: Gender, Sexuality, Teacher's training. 
Uma aluna contou-me a seguinte situação vivida em sala de aula: Paulo, de seis anos, durante uma atividade, resolveu ir brincar de boneca com as meninas, deixando de lado os demais meninos e os carrinhos. De forma discreta e inteligente, a professora observou sem intervir, até que foi chamada aos gritos por duas ou três crianças da turma para ir lá ver o Paulo que tinha engravidado: "Professora, vem ver! O Paulo vai ter neném!". Ela respirou fundo e se aproximou. Meninos e meninas estavam afoitos em torno do Paulo, que havia colocado uma das bonecas embaixo da camiseta enquanto outro pedia para ele deitar "pra fazer a criança nascer". A professora prosseguiu sem intervir até que, ao ver a encenação da boneca sendo retirada da barriga do Paulo, meio sem jeito, resolveu perguntar qual era o nome da criança: "Que linda. Como ela vai se chamar?". Paulo rapidamente respondeu: “Vitória!". Na tentativa de acabar com a encenação sem demonstrar todo o estranhamento que estava sentindo, e com certo pânico de outras professoras da creche verem que ela havia entrado no jogo transgressivo das crianças, tentou desviar a atenção do grupo fazendo outra pergunta: "Que legal. E agora o que você vai fazer com ela?". Paulo pensou, fez um instante de silêncio e disse, levantando-se e entregando a boneca para a menina que estava ao seu lado: "Eu vou dar pra mãe dela cuidar e vou trabalhar".

Além de compreendermos que o transgressivo tem uma determinada temporalidade, que não é algo necessariamente fixo e estável, o relato me parece interessante porque sempre que o conto, durante a narrativa, quem está ouvindo fica tenso/ tensa com a possibilidade de isso acontecer com ele/ela, mas no final dá uma gargalhada, liberando toda a tensão, quando percebe que foi só uma brincadeira e que Paulo volta, no final da história, a corresponder ao que se espera de um futuro "homem", isto é, que trabalhará fora enquanto a mulher cuidará da criança.

Esse e outros relatos que apresentarei neste texto refletem o quanto a temática da sexualidade e do gênero é pertinente diante da formação de professores/as, especialmente em relação àqueles/as profissionais que trabalharão ou trabalham na Educação Infantil, ou com as séries iniciais do Ensino Fundamental, afinal, é nesse período que as crianças participarão de um grupo social mais amplo do que o da família, que as coloca em um palco de inscrições intelectuais, sociais e psicológicas (VIANNA; FINCO, 2009).

Segundo o que observo, essa temática tem sido abordada em diferentes espaços de formação desses profissionais. Às vezes aparece no programa do curso, ou surge de forma quase inesperada enquanto demanda pertinente ao debate atual sobre educação. Aqui, mais do que uma análise conclusiva via uma metodologia estruturada, procuro descrever e refletir teoricamente sobre essas experiências educativas que revelam compreensões, dilemas e facilidades diante desse tema.

Essas experiências referem-se a relatos que colhi enquanto professor das turmas vinculadas ao Plano Nacional de Formação de Professores da Educação Básica (PARFOR), do curso de Pedagogia na Pontifícia Universidade Católica de Campinas (PUC Campinas), e como tutor do curso Gênero e Diversidade na Escola (GDE), oferecido à distância pela Universidade Federal de São Carlos (UFSCar) e a Universidade Aberta do Brasil (UAB), voltado a professores/as de diferentes anos do Ensino 
Fundamental. Oficinas junto a estudantes e diferentes profissionais da educação desenvolvidas pelo Identidade - Grupo de Luta pela diversidade sexual -, no qual tenho atuado nos últimos anos, também fazem parte das experiências que me possibilitaram reunir relatos sobre esse tema.

Além disso, reflito a partir do trabalho de campo feito durante o estudo qualitativo sobre a homofobia no ambiente escolar em 11 capitais brasileiras, realizado pela Organização Não Governamental Reprolatina - Soluções Inovadoras em Saúde Sexual e Reprodutiva. Os dados do relatório técnico final, produzido por esta instituição, também são citados ao longo do texto. $\mathrm{O}$ foco da pesquisa foram autoridades educacionais, equipe docente e estudantes do $6^{\circ}$ ao $9^{\circ}$ ano do Ensino Fundamental. ${ }^{1}$

Através de um referencial teórico sobre gênero e sexualidade, em uma perspectiva pós-estruturalista, penso a formação de professores/as a partir dessas múltiplas experiências que trago na memória. Aqui, não focarei somente nos relatos colhidos, mas também nos contextos e relações deste pesquisador e professor com os/as estudantes e/ou profissionais. Afinal, as crianças e os adolescentes da Educação Básica, os professores em formação e nós, que trabalhamos com a formação de professores, somos constituídos (às vezes por adesão e às vezes por contestação) das mesmas lógicas de gênero e sexualidade e, por isso, precisamos nos situar e pensar nesse tema também a partir das nossas próprias experiências como professores/as.

\section{A importância da formação em gênero e sexualidade}

O relato da brincadeira do Paulo feito em diferentes salas de aulas sempre me permitiu introduzir o tema do gênero e da sexualidade. Nessas situações, percebo que a maior dificuldade no processo de formação de professores/as quando o assunto é sexo e gênero é a compreensão de que, historicamente, as diferenças de gênero precederam as diferenças de sexo.

Laqueur (2001) foi um dos que afirmou que o sexo é tão contextual quanto o humano. Ele nos lembra, por exemplo, de que o lugar-comum de parte da psicologia contemporânea (frequentemente mantido por um discurso biologizante da "natureza dos sexos"), de que o homem deseja sexo e a mulher deseja relacionamentos, é a exata inversão das noções do pré-iluminismo que, desde a Antiguidade, ligava as amizades aos homens e a sensualidade às mulheres.

Assim, ao pensarmos em sexualidade e gênero, é fundamental compreender que é um equívoco acreditar em uma base natural que é binária e sexuada (entendida como uma diferença sexual pautada em dois sexos opostos e complementares, dos quais não teríamos como fugir), onde a cultura simplesmente age sobre o que já está definido como macho ou fêmea. ${ }^{2}$ Nesses termos, explica Bento:

O original já nasce "contaminado" pela cultura. Antes de nascer, o corpo já está inscrito em um campo discursivo. Após o nascimento da criança, as tecnologias discursivas dirigem-se à preparação do corpo para que desempenhe com êxito o gênero. $O$ mundo infantil se constrói sobre proibições e afirmações. Essa pedagogia dos gêne- 
ros hegemônicos tem como objetivo preparar os corpos para a vida referenciada na heterossexualidade, construída a partir da ideologia da complementaridade dos sexos. As "confusões" nos "papéis" provocam, direta e imediatamente, "perturbações" na orientação sexual, supõem os defensores do binarismo. (BENTO, 2011, p. 550-551)

Diferentemente da situação vivida por Paulo, em que a professora não o repreendeu por ter "trocado de sexo" na brincadeira, outros casos podem ser pensados a partir deste contexto de proibições e afirmações, para que o sexo e o gênero correspondam ao esperado pelo discurso hegemônico, especialmente quando se trata de crianças mais velhas, caso em que se pode imaginar que o que se passa já não é somente uma brincadeira inofensiva, em termos de fluidez em relação a sexo e gênero. Por exemplo, na pesquisa realizada pela Reprolatina, foi unânime a rejeição por parte da comunidade escolar da possibilidade de uso do banheiro feminino por garotos efeminados ou travestis adolescentes. As justificativas para a negação desse uso, que muitos têm defendido como sendo um direito, apontam para o perigo de que, antes de tudo, estamos tratando de "menores", e por outro lado, "os pais não iriam gostar" (REPROLATINA, 2012, p. 41). Alguns chegaram a afirmar que seria contra as leis! Assim, "a educação infantil não só cuida do corpo da criança, como o educa: ele é o primeiro lugar marcado pelo adulto, em que se impõem à conduta dos pequenos os limites sociais e psicológicos. É o emblema no qual a cultura inscreve seus signos"(VIANNA; FINCO, 2009 , p. 271). Nesse sentido, a formação dos/as profissionais ligados/as a este período é essencial para a garantia do reconhecimento à diversidade, inclusive a de gênero e a sexual. Os professores que atuam nos anos finais da Educação Básica também carecem de formação, segundo o que apontou o relatório final da pesquisa nas onze capitais brasileiras. Uma das recomendações, frequentemente dada pelos participantes da pesquisa foi a de "capacitar educadores para implementar a educação sexual que inclua as diversidades sexuais e a identidade de gênero" (REPROLATINA, 2011, p. 63).

\section{Os estranhamentos e o limitado discurso do respeito às diferenças}

Mesmo com o trabalho pedagógico contínuo, repetível e interminável para inscrever nos corpos o gênero e a sexualidade "legítimos", esse processo é afeito a instabilidade, é permeável aos acidentes, e, por ser como tudo que é histórico e cultural, o gênero e a sexualidade guardam inconstâncias, permitindo que muitos escapem da via planejada, coloquem-se à deriva ou vão buscar outro lugar para se alojar ou se mover (LOURO, 2004). Em outras palavras, há transgressões de diferentes ordens. O mais incrível dessas transgressões é que elas denunciam, se por um lado o poder das nossas normas, por outro, o quanto estas são contingenciais e falíveis. E, quando pensadas nessa perspectiva, especialmente sendo problematizadas em espaços formativos, desvelam-se facilmente como algo passível de mudança. Ainda, o mais incrível é que quando damos visibilidade a essas transgressões e, especialmente, ao quanto elas demonstram a falibilidade das nossas normas, descobrimos que são muitas e acontecem em todos os lugares. Por exemplo, ouvi em meio a uma discussão teórica a seguinte frase: "Eu tenho um caso desses lá na minha creche". A questão era a experiência de crianças intersex ${ }^{3}$. Eu comentava o caso para discutir o quanto é fundamental na for- 
mação de professores/as a desconstrução das categorias naturalizadas por nossa cultura, como, por exemplo, a de "sexo".

Então, algo que estava aparentemente tão longe e distante materializou-se na sala de aula através do relato da estudante. No contexto do seu trabalho, a identificação da criança como sendo masculina ou feminina (esse é o grande eixo das discussões sobre intersexualidade em diferentes campos do conhecimento científico e até mesmo entre organizações dos direitos humanos ${ }^{4}$ ) foi feita a partir do sexo do irmão gêmeo da criança intersex. Como o irmão, que nasceu no mesmo dia, por não ser intersex, foi facilmente classificado como "menino", a ela também foi dada a mesma classificação.

Problematizar não só a atitude das funcionárias da creche, mas também as atitudes médicas a respeito da decisão em intervir no corpo dos intersexos, causou muito estranhamento em sala de aula. Afinal, essas experiências suscitam

[...] importantes reflexões acerca de como os corpos são construídos em nossas sociedades e sua importância biopolítica para a construção das identidades, assim como o estranhamento causado por corpos que não se enquadram nos ideais normativos e que "precisam" ser des-feitos para atingir um mínino de humanidade. (PINO, 2007, p. 169)

Para Vianna e Finco (2009), a estranheza é o primeiro sentimento que as crianças transgressoras causam nas professoras. Durante parte da pesquisa de campo para a Reprolatina, vários/as professores/as assumiram ter a mesma reação. No relatório técnico final consta um depoimento com esse teor: "Jamais vou tratar diferente, mas lá no meu íntimo assim, parece que não é algo normal, né? Uma coisa meio estranha" (REPROLATINA, 2011, p. 40). Ainda segundo estas autoras, "Tal estranheza deriva da exposição do que todos esperavam que se mantivesse oculto e restrito." (VIANNA; FINCO, 2009, p. 280).

O mesmo se passa no ambiente virtual de aprendizagem. $\mathrm{O}$ jeito de escrever as histórias das crianças "estranhas" no ambiente virtual e de debatê-las, isto é, a forma de usar as palavras, de pontuar as frases, o excesso de espaçamentos entre estas e o tempo que vai levar para alguém responder à postagem de um relato com conteúdo desse tipo, são alguns sinais de o quanto o estranhamento está para além das relações de ensino-aprendizado face a face.

Outro exemplo diz respeito à minha própria atuação enquanto professor quando, no primeiro contato com as/os estudantes, apresento-me dizendo que o meu tema de pesquisa no mestrado foi a questão dos gêneros, das sexualidades e dos desejos disparatados de travestis adolescentes (DUQUE, 2011). As reações de estranhamento são visíveis pelas expressões faciais e também pelo silêncio que se segue no aguardo de maiores esclarecimentos, porque, a princípio, trata-se de um tema absolutamente risível, ou parece não ser possível que ele possa ser tratado como foco de pesquisa científica, e, ainda mais, que seja colocado assim, digamos, de forma tão natural em uma apresentação pessoal no primeiro dia de aula. Esse clima desconcertante não ocorre somente em salas de aulas do curso de Pedagogia. No próprio curso de Ciências So- 
ciais já passei por isso. Ele se instala porque nós, professores/as, raramente falamos do prazer e do desejo erótico em nossas salas de aula.

Treinadas no contexto filosófico do dualismo metafísico ocidental, muitas de nós aceitamos a noção de que há uma separação entre o corpo e a mente. Ao acreditar nisso, os indivíduos entram na sala de aula para ensinar como se apenas a mente estivesse presente, e não o corpo. Chamar a atenção para o corpo é trair o legado da repressão e de negação que nos tem sido passado por nossos antecessores na profissão docente [...] O mundo público da aprendizagem institucional é um lugar onde o corpo tem de ser anulado, tem que passar despercebido. (HOOKS, 2001, p. 115)

Há ainda, portanto, diante de um possível estranhamento, a tendência de buscar invisibilizar a sexualidade, como se ela fosse um assunto privado, ou que não pertence à escola. Essa postura ficou absolutamente perceptível em várias situações vivenciadas durante o trabalho de campo na pesquisa feita nas capitais. Um dos profissionais da Educação chegou a afirmar: "Aqui, pra nós, todos são tratados da mesma forma, não tem menino ou menina, sexualidade é do portão pra fora". Uma autoridade de Estado reforçou: "Alunos, são todos iguais, não têm sexo..." (REPROLATINA, 2011, p. 20).

Mas se essas atitudes incomodam "[...] é sinal de que surgiu a oportunidade de quebrar o silêncio e trazer à luz um assunto que pode contribuir para repensar a diversidade sexual e afetiva dos seres humanos" (MISKOLCI, 2005, p.17). Porque, sabemos, o silêncio de educadores, e aqui entendo inclusive os educadores responsáveis pela formação de professores/as, diante do incômodo causado por um relato ou até mesmo por uma situação "estranha" envolvendo gênero e sexualidade vivida em sala de aula, não é uma atitude neutra. "Fingir que alguém não existe nada tem de imparcial, e ignorar costuma ser a melhor forma de fazer valer os padrões de comportamento considerados 'bons', 'corretos', 'normais”'. (Ibidem, p. 18).

Sabendo disso, em certa ocasião, em um curso onde estava começando a trabalhar, vi uma aluna que embaralhou a minha inteligibilidade de gênero e de sexualidade. Desconcertado, perguntava-me se ela seria uma travesti ou transexual. Como em pouco tempo teria que fazer a chamada pelo nome da lista de presença, e, certamente, lá não constaria o seu nome social, pensava comigo mesmo: "Como vou chamá-la pelo nome de registro se lutamos tanto pelo reconhecimento da feminilidade trans?"; "Mas, e se ela não for travesti ou transexual?".

Essas perguntas me passaram pela cabeça, fazendo-me sentir e vivenciar como se dá o estranhamento em sala de aula em reação à inteligibilidade do gênero e da sexualidade, e como estamos todos/as envoltos/as em dificuldades semelhantes.

Tentando não demonstrar nervosismo, fiz o que orientamos (às vezes friamente ou de forma tão hipotética que não imaginamos que iremos passar por isso) em nossas oficinas do movimento social: independentemente de estarmos ou não de frente para um grupo em que haja alguém que nos cause estranheza quanto à questão do gênero ou da sexualidade, devemos sempre oferecer a oportunidade para que todos/ 
as possam ter o direito de serem chamados/as ou identificados/as como desejarem, independentemente do registro nos documentos pessoais ou escolares.

Então, antes de começar a chamada, sugeri que, se houvesse alguém na sala com um nome de registro que não se identificasse, que fosse até mim naquele momento para que eu pudesse anotar o nome adotado socialmente no diário. Outra mulher que havia passado despercebida por mim se levantou e se aproximou dizendo que, por favor, eu não a chamasse pelo primeiro nome, somente pelo segundo. Ninguém mais se pronunciou. Por um lado, eu havia me enganado em relação à minha suspeita, por outro, aprendi o quanto, por estudarmos, pesquisarmos e ensinarmos sobre questões que envolvem sexualidade e gênero em uma perspectiva da diversidade sexual, não estamos livres dos estranhamentos que envolvem o que temos historicamente construído e identificado como sendo "normal" e "não normal", afinal, também somos compostos pelas mesmas normas hegemônicas de construção do gênero e da sexualidade. Isso torna mais urgentes o aprendizado e o ensino de que:

[...] é um equívoco falar em "diferença ou diversidade no ambiente escolar" como se houvesse o lado da igualdade, onde habitam os/ as que agem naturalmente de acordo com os valores hegemônicos e os outros, ou diferentes. Quando, de fato, a diferença é anterior, é constitutiva dessa suposta igualdade. Portanto, não se trata de "saber conviver", mas considerar que a humanidade se organiza e se estrutura na e pela diferença. Se tivermos essa premissa evidente, talvez possamos inverter a lógica: não se trata de identificar "o estranho" como "o diferente", mas de pensar que estranho é ser igual e na intensa e reiterada violência despendida para se produzir o hegemônico transfigurado em uma igualdade natural. (BENTO, 2011, p. 556)

Por isso, reconheçamos, não estamos tratando de algo que seja pouco complexo ou facilmente resolvível. Como explicarei a seguir, é fundamental partirmos da necessidade de propor uma formação de professores/as que leve o respeito às diferenças para além do simples reconhecimento da diversidade. Afinal,

O risco é que o respeito e o reconhecimento da diferença se reifiquem numa espécie de mera 'celebração da singularidade' ou elogio à diferença, frequentemente estetizada e quase invariavelmente engessada. (JUNQUEIRA, 2009, p. 400)

Sendo assim, respeitar ou reconhecer a diferença precisa ser problematizado no sentido de garantir que na formação de professores/as sejam consideradas as histórias, as necessidades, as reivindicações e as especificidades de indivíduos ou grupos, e, juntamente com isso, como defende Junqueira quando pensa a respeito das diferenças no campo da educação, é preciso:

[...] considerar as circunstâncias sociais, políticas e históricas da produção da diferença, as relações assimétricas que nortearam e norteiam sua produção e os conjuntos de representações sociais em circulação. Por conseguinte, em nome do reconhecimento e do respeito à diferença, não podemos nos sentir desobrigados de exercer a crítica aos processos em que, no curso de sua construção, distinções, 
fronteiras e hierarquizações são propostas, impostas ou mantidas, e semelhanças são negadas e convergências, desestimuladas. (JUNQUEIRA, 2009, p. 399)

Um início possível para pensar formação de professores/as nestes termos é deixar emergir a diferença. Proponho, para isso, levarmos em consideração as reflexões de Macedo (2010) sobre a escola, mas considerando o espaço universitário da formação dos/as profissionais da educação. Para ela, "[...] uma escola que deixa emergir a diferença é, portanto, aquela que desconstrói as fixações e permite que a cultura apareça como prática de dar sentido ao mundo" (MACEDO, 2010, p. 35). Ela faz uma contraposição às alternativas que tratam da diversidade cultural contemporânea (incluindo aí a questão do gênero e da sexualidade) como concebendo cultura ou culturas como fonte de conteúdos, procedimentos e valores. "Um repertório de onde se pode selecionar o que ensinar e o que aprender para se tornar alguém” (Ibidem, p. 24). Segundo a autora, infelizmente esses repertórios deixam de lado o presente da produção de sentidos que acontece no espaço da escola, para lidar com o passado da cultura e o futuro do projeto do sujeito. Por isso, em alguns casos, eles são alternativas que permitem lidar com a diversidade, mas não com a diferença.

O principio central de uma escola comprometida com a diferença deve ser o respeito ao Outro, como aquilo que não pode ser pensado a priori, definido de antemão. Nessa escola, as pessoas não se tornam porque a completude do processo de tornar-se só seria possível se eliminássemos para sempre a diferença. Elas seguem se constituindo sempre outras, ainda que sem deixar de ser elas mesmas. (Ibidem, p. 36)

Assim, se pensarmos e agirmos a partir da emergência das diferenças, nós, professores/as que atuamos na formação de professores/as, estaremos igualmente reconhecendo que o processo de formação também se concretiza em nós. Por isso, convém que façamos aquilo que sugerimos, afinal, como já mencionei, somos constituídos por normas de gênero e sexualidade que também estão postas (ainda que passíveis de contestações e transgressões) para as/os estudantes de nossas salas, como para as crianças com que elas/eles já trabalham ou irão trabalhar.

\section{Formação de professores/as para além da escola: a título de conclusão}

Segundo Beleli (2010, p. 58), "a responsabilidade pela formação infantil, atribuída ora à família, ora à escola, é um fator que tenciona as relações entre a criança, a escola e a família". O próprio campo da pesquisa sobre homofobia nas escolas revelou isso de forma perturbadora: muitos/as professores/as não atuam em prol da diversidade sexual por medo das cobranças dos pais ou, pelo menos, usam desse argumento para justificar seu não envolvimento ou abordagem do tema. Isso foi recorrente em todas as capitais:

[...] as e os professores reconhecem que não aplicam muitas das recomendações estabelecidas nas políticas e planos anuais porque sentem que não estão preparados para atuar na área das diversidades 
sexuais e da homofobia e também porque temem que as famílias se oponham a que esses temas sejam tratados nas escolas. (REPROLATINA, 2011, p. 65)

Por outro lado, alguns/algumas educadores/as estão desenvolvendo estratégias de respeito à diferença sem necessariamente envolver as famílias. Por exemplo, segundo uma aluna, em determinada escola de educação infantil, as professoras autorizaram os meninos interessados em brincar na casinha de bonecas a entrar e se divertir com as meninas da turma. O previsível aconteceu: alguns pais começaram a reclamar ao saber que seus filhos às vezes deixavam os carrinhos para brincar com as bonecas e panelinhas. "Eles ficavam loucos para entrar lá, choravam. Nós não iríamos deixar?!", contava-me a aluna-professora referindo-se aos desejos dos meninos. Então, segundo ela, a equipe decidiu tomar uma atitude que, se por um lado foge ao necessário enfrentamento pedagógico junto aos pais, por outro, garante que os brinquedos sejam partilhados por todos/as. Em vez de entrar em um processo de convencimento dos pais, que poderia não ter resultado prático imediato, a equipe passou a chamar a casinha de bonecas de casinha lúdica. A mudança do nome da casinha driblou a censura daqueles pais mais incomodados.

Em outro relato, o pai fez uma confusão porque chegou à escola e viu o filho ninando uma boneca. $\mathrm{Na}$ ocasião, explicaram para o pai que, como ele, o filho dele se casaria, "ajudaria em casa" e também seria pai, e que precisaria aprender a cuidar de uma criança. Nesse caso, se por um lado garantiu-se o acesso do menino à boneca, por outro a motivação para a justificativa ainda foi limitada, afinal, a única possibilidade de justificarmos a troca de brinquedos é no sentido de legitimar a imagem de um suposto homem heterossexual moderno e paternal?

No entanto, no mesmo ambiente cultural que reforça posturas padronizadas, permite-se também o exercício da crítica, como no caso da professora que se recusou a colocar ícones masculinos ou femininos no banheiro que tinha disponível em sua sala de aula. As crianças entravam e viravam a plaquinha na porta apenas para dizer se havia (círculo na cor vermelha) ou não (círculo na cor verde) alguém ali, se o local estava ocupado ou desocupado, independentemente de se por menino ou menina. As amigas de trabalho a criticaram pela ideia de construir um banheiro "unisex".

Sabemos que é comum a crítica individual não encontrar:

[...] um ambiente institucional que a fortaleça e que favoreça situações intencionadas de construção de novos signos em um projeto coletivo de reflexão sobre o papel da instituição de Educação Infantil na constituição das subjetividades masculinas e femininas. (SILVA; LUZ, 2010, p. 37)

Por isso, precisamos pensar na formação em gênero e sexualidade não só para além da sala de aula e das famílias das crianças matriculadas na Educação Básica, mas também para além das instituições formadoras de professores/as. Não dá para criar um cenário simplista de culpados e vítimas. É preciso reconhecer que todas estas instituições não estão soltas no mundo. Mesmo porque, afinal, 
[...] nas sociedades contemporâneas, o prestígio de uma profissão mede-se, em grande parte, pela sua visibilidade social. No caso dos professores estamos mesmo perante uma questão decisiva, pois a sobrevivência da profissão depende da qualidade do trabalho interno nas escolas, mas também da sua capacidade de intervenção no espaço público da educação. Se os programas de formação não compreenderem esta nova realidade da profissão docente passarão ao lado de um dos principais desafios deste princípio do século XXI. (NÓVOA, 2009, p. 44)

Entretanto, não se pode entender o que problematizamos aqui como algo que diz respeito apenas ao campo restrito da formação de professores/as. Por exemplo, como aponta Nunes (2009), é preciso ter em vista a compreensão da educação infantil como um produto histórico, e do/da profissional da educação infantil como um sujeito que tem a sua produção de saberes e de práticas mediada e condicionada pela maneira como o Estado enfrenta, no plano ideológico-político, os desafios postos pelas desigualdades sociais, afinal

[...] a questão da profissionalização do educador infantil ocorre num ambiente em que a área social está contaminada por projetos societários conservadores, articulados à perspectiva neoliberal de satanização do Estado e de beatificação da sociedade civil, que dão o formato ideal para a desregulamentação das relações trabalhistas. $\mathrm{O}$ enfrentamento desse dilema certamente depende do grau de mobilização e de politização dos profissionais de educação em geral, e da educação infantil em particular. (Ibidem, p. 90)

Isso tudo, no entanto, não tira a nossa responsabilidade de abordarmos sexualidade e gênero na formação de professores/as, isto é, de oferecermos os elementos para a sua qualificação crítica diante da realidade. Por isso, o nosso compromisso com uma discussão pós-estruturalista para a educação é cada vez mais necessário e urgente, especialmente para a questão da formulação dos currículos da formação de professores/as. Um currículo partindo desse pressuposto teórico força os limites das epistemes dominantes: "não se limita a questionar o conhecimento como socialmente construído, mas que se aventura a explorar aquilo que ainda não foi construído" (SILVA, 1999, p. 109).

Assim, neste artigo, busquei refletir sobre o quanto nós devemos enfrentar o desafio de problematizar as normas de gênero e sexualidade na formação de professore/as para além do respeito à diversidade, isto é, para além da crença na existência de um grupo dos/as iguais e em um grupo dos/as diversos. A questão está em pensarmos sobre o modo como queremos interagir com a diferença - se ficaremos no estranhamento normalizador e na melhor das hipóteses respeitável, ou se usaremos da visibilidade da diferença como aposta nas experiências de gênero e sexualidade ainda não vividas.

\section{Referências}

BELELI, I. "Gênero". In: MISKOLCI, R. (Org.). Marcas da diferença no ensino escolar. São Carlos, EdUFScar, 2010. p. 45-55. 
"Professora, vem ver! O Paulo vai ter neném!": gênero, sexualidade e formação de professores/as

BENTO, B. "Na escola se aprende que a diferença faz a diferença”. In: Estudos Feministas, Florianópolis, n. 19(2), 2011.p. 549-559. Disponível em: <http://www.periodicos.ufsc.br/index. $\mathrm{php} / \mathrm{ref} /$ article/view/21485/19404>. Acesso em: 12 dez. 2012.

DUQUE, T. Montagens e desmontagens: desejo, estigma e vergonha entre travestis adolescentes. São Paulo: Annablume, 2011.

HOOKS, B. "Eros, erotismo e o processo pedagógico". In: LOURO, G. L. (Org.). O corpo educado: pedagogias da sexualidade. Belo Horizonte: Autêntica, 2001. p.113-123.

JUNQUEIRA, R. D. "Educação e homofobia: o reconhecimento da diversidade sexual para além do multiculturalismo liberal”. In: (Org.). Diversidade sexual na educação: problematizações sobre homofobia nas escolas. Brasília: Ministério da Educação, Secretaria de Educação Continuada, Alfabetização e Diversidade, UNESCO, 2009. p. 367-444. Disponível em: <http://unesdoc.unesco.org/images/0018/001871/187191por.pdf>. Acesso em: 10 nov. 2012.

LAQUEUR, T. W. Inventando o sexo: corpo e gênero dos gregos a Freud. Rio de Janeiro: Relume Dumará, 2001.313p.

LOURO, G. L. Um corpo estranho - ensaios sobre sexualidade e teoria queer. Belo Horizonte: Autêntica, 2004.90p.

MACEDO, E. A Cultura e a escola. In: MISKOLCI, R. (Org.). Marcas da diferença no ensino escolar. São Carlos, EdUFScar, 2010. p. 12-38.

MISKOLCI, R. Um corpo estranho na sala de aula. In: ABRAMOWICZ, A.; SILVÉRIO, V. R. Afirmando diferenças: montando o quebra-cabeça da diversidade na escola. Campinas: Papirus, 2005. p. 13-26.

NÓVOA, A. Professores: imagens do futuro presente. Lisboa: EDUCA. 2009. 96p.

NUNES, D. G. Educação infantil e mundo político. Revista Katálysis. Florianópolis. v. 12. n. 1, p. 86-93, jan./jun. 2009.

PINO, N. P. A teoria queer e os intersex: experiências invisíveis de corpos desfeitos. Cadernos Pagu, Campinas: Núcleo de Estudos de Gênero Pagu/UNICAMP, n. 28, 2007. p. 101-128. Disponível em: <http://www.scielo.br/pdf/cpa/n28/08.pdf> Acesso em: 23 set. 2012.

REPROLATINA. Estudo qualitativo sobre homofobia no ambiente escolar em 11 capitais brasileiras (relatório técnico final). Projeto Escola sem Homofobia - componente de pesquisa. 2011.

SILVA, I. de O.; LUZ, I. R. da. Meninos na Educação Infantil: o olhar das educadoras sobre a diversidade de gênero. In: Cadernos Pagu, Campinas: Núcleo de Estudos de Gênero Pagu/ UNICAMP, n. 34, 2010. p. 17-39. Disponível em: <http://www.scielo.br/pdf/cpa/n34/a03n34. pdf>. Acesso em: 13 nov. 2012.

SILVA, T. T. da. Documentos de identidade: uma introdução às teorias que currículo. Belo Horizonte: Autêntica, 1999. 156p.

VIANNA, C.; FINCO, D. Meninas e meninos na Educação Infantil: uma questão de gênero e poder. In: Cadernos Pagu, Campinas: Núcleo de Estudos de Gênero Pagu/UNICAMP, n. 33 2009, p. 265-283. Disponível em: <http://www.scielo.br/pdf/cpa/n33/10.pdf>. Acesso em: 10 out. 2012 
${ }^{1}$ Esse estudo foi um dos componentes do Projeto Escola sem Homofobia, coordenado pela Pathfinder do Brasil em parceria com a Reprolatina, Associação Brasileira de Lésbicas, Gays, Bissexuais, Travestis e Transexuais (ABGLT) e ECOS - Comunicação em sexualidade. A pesquisa, discutida previamente pelos parceiros, obteve aprovação e apoio da Secretaria de Educação Continuada, Alfabetização e Diversidade (SECAD) do MEC.

2 "Não se pretende, com isso, negar a materialidade dos corpos, mas o que se enfatiza são os processos e as práticas discursivas que fazem com que aspectos dos corpos se convertam em definidores de gênero e de sexualidade e, como conseqüência, acabem por se converter em definidores dos sujeitos”. (LOURO, 2004, p. 80)

3 "Intersex é uma definição geral usada para explicar a variedade de condições nas quais as pessoas nascem com órgãos reprodutivos e anatomias sexuais que não se encaixam na típica definição de masculino ou feminino". (PINO, 2007, p. 153)

${ }^{4}$ Hoje há, em diferentes países do mundo, uma tentativa de ativistas de banir as cirurgias que desfazem e refazem esses corpos "estranhos", porque elas não garantem que ao crescer aquela criança vai se identificar/ reconhecer com o sexo anatômico feito à base de cirurgias. No entanto, é importante ressaltar que "[...] a medicina não é a grande vilã da história, antes, é parte da ordem social que exige que as pessoas tenham um sexo verdadeiro - homem-masculino e mulher-feminina - e que essa verdade esteja sinalizada no corpo". (PINO, 2007, p. 171)

* Doutorando em Ciências Sociais pela Pontifícia Universidade Católica de Campinas e professor da Universidade Federal de Mato Grosso do Sul - Campus Pantanal (UFMS/CPAN). Campo Grande, Mato Grosso do Sul, Brasil.

\section{Correspondência}

Tiago Duque - Avenida Rio Branco 1.270 Universitário, CEP: 79230000 - Universidade Federal de Mato Grosso do Sul. Corumbá, Mato Grosso do Sul - Brasil.

E-mail:duque_hua@yahoo.com.br

Recebido em 13 de março de 2013

Aprovado em 12 de agosto de 2014 